\title{
Analysis of Static Instability of an Asymmetric, Rotating Sand-Wich Beam
}

\author{
P. R. Dash, ${ }^{1}$ K. Ray, ${ }^{2}$ S. K. Sarangi, ${ }^{1}$ and P. K. Pradhan ${ }^{1}$ \\ ${ }^{1}$ Mechanical Engineering Department, VSSUT Burla, Orissa 768018, India \\ ${ }^{2}$ Mechanical Engineering Department, IIT Kharagpur, Kharagpur 721302, India \\ Correspondence should be addressed to P. K. Pradhan, prasant2001uce@gmail.com
}

Received 16 May 2011; Accepted 8 August 2011

Academic Editor: Joseph CS Lai

Copyright () 2012 P. R. Dash et al. This is an open access article distributed under the Creative Commons Attribution License, which permits unrestricted use, distribution, and reproduction in any medium, provided the original work is properly cited.

\begin{abstract}
The static stability of an asymmetric, rotating sandwich beam subjected to an axial pulsating load has been investigated for pinnedpinned and fixed-free boundary conditions. The equations of motion and associated boundary conditions have been obtained by using the Hamilton's energy principle. Then, these equations of motion and the associated boundary conditions have been nondimensionalised. A set of Hill's equations are obtained from the nondimensional equations of motion by the application of the general Galerkin method. The static buckling loads have been obtained from Hill's equations. The influences of geometric parameters and rotation parameters on the nondimensional static buckling loads have been investigated.
\end{abstract}

\section{Introduction}

The dynamic behavior of rotating beams is of great practical interest in the design of steam and gas turbine blades and helicopter blades. Sandwich constructions with high strength facings and a light weight core have been very popular in aerospace applications. Typical sandwich members used varied from structural panels in aircraft to the helicopter rotor blades. In general, high modulus and light weight characteristics of the sandwich construction normally have great advantages of high movability, power saving, and high strength in robotics applications. Extensive publications have been available concerning the design and analysis of sandwich structures.

Bhat [1] studied the natural frequencies and mode shapes of a rotating uniform cantilever beam with tip mass for different values of rotational speed, hub radius, and setting angle using beam characteristic orthogonal polynomials in the Rayleigh-Ritz method. Liu and Yeh [2] presented the natural frequencies of a nonuniform rotating beam with a restrained base for various values of restraint parameters and rotational speed. Unger and Brull [3] made an analytical investigation to determine the simple and combination resonance regions of shafts mounted in a long and short bearings subjected to pulsating torque applied at the ends and found that the most common and dangerous parametric instabilities arose as a result of combination resonance. Kammer and Schlack [4] obtained the boundaries between the stable and unstable regions of an Euler beam rotating with an angular velocity which has a small periodic component. Sri Namachchivaya [5] derived explicit stability conditions for a rotating shaft under parametric excitation comprising a combination of harmonic terms and stationary stochastic processes using the Routh-Hurwitz criterion and found that the addition of nonwhite noise excitation has a stabilizing effect on harmonically excited shafts. The vibration behavior of a rotating beam, oriented perpendicular to the axis of spin, was investigated by Bauer and Eidel [6]. It was observed that the speed of rotation has a very pronounced influence of the rotating beam and an increase in the speed of rotation may increase or decrease the natural frequencies depending on the boundary conditions. Abbas and Thomas $[7,8]$ studied the effect of rotational speed and root flexibilities on the first-order simple resonance zones of a rotating Timoshenko's beam by using the finite element method. Bauchau and Hong [9] utilized the same method to analyze the effect of viscous damping on the response and stability of parametrically excited beams undergoing large deflections and rotations. Dynamic stability of an ordinary rotating beam with various boundary conditions was studied by Kar 
and Sujata [10]. The same authors [11] also studied the stability of a rotating, pretwisted and preconed cantilever beam. Parametric instability of a rotating pretwisted beam subjected to sinusoidal compressive axial loads was addressed by Tan et al. [12].

As it has been pointed out by many investigators the shear deformation of the core plays an important role in the flexural and dynamic behavior of a sandwich beam; therefore, the flexural rigidity in the core and shear deformation of the facings were neglected in many analysis. The parametric instability of a cantilever beam with magnetic field and periodic axial load has been studied by Pratiher and Dwivedy [13]. The results obtained from perturbation analysis have been verified by solving the temporal equation of motion using fourth-order Runge-Kutta method. Dwivedy et al. [14] have investigated the parametric instability regions for simple supported, clamp-guided, clamp-free riveted, and clamped-free end condition by modified Hsu's method and found that zones of instability are affected by the shear parameter, core-loss factor and the ratio of core thickness to skin thickness. Zheng et al. [15] investigated the instability of a moving load system with the load approximated as a single-axle mass-spring-damper system. The author showed that instability occurs for a lower mass as compression axial force increases. Metrikine and Verichev [16] introduced two degrees of freedom load and approximated the rail as a Timoshenko beam. They have observed that under these approximations, larger mass of the load lowers the velocity at which instability is observed. The same authors [17] have considered the effect of periodic variations of the foundation stiffness on instability. The parametric instability of viscoelastically supported asymmetric sandwich beam have been studied by Ghosh et al. [18] and found that the viscoelastic constraints improve the stability of the system. The dynamic stability of a rotating sandwich beam using the finite element method has been studied by Lien and Chen $[19,20]$. The parametric instability of a rotating asymmetric sandwich beam with viscoelastic core and subjected to a pulsating axial load has been studied by Dash et al. [21].

The present work deals with the static stability of a rotating asymmetric sandwich beam subjected to axial pulsating load, since it has not been studied till now. The equations of motion for transverse vibrations of the beam are obtained using Hamilton's principle. The general Galerkin method is used to reduce the nondimensional equations of motion to a set of coupled Hill's equations with complex coefficients. The static buckling loads are obtained from Hill's equations [22]. The effect of rotation parameters and geometric parameters on the nondimensional static buckling loads is investigated for the pinned-pinned and fixed-free boundary conditions.

\section{Formulation of the Problem}

2.1. System Configuration. A viscoelastic sandwich beam of length $l$ and width $B$, set off at a distance $b$ from the axis of rotation $\left(z^{\prime}\right.$-axis) and oriented along the $x$-axis, perpendicular to the axis of rotation is shown in Figure 1. The beam rotates about the vertical $z^{\prime}$-axis at a constant angular velocity $\Omega_{0}$ and is capable of oscillating in the $x-z$ plane. It is asymmetric with respect to the $x-y$ plane as layer 1 is not same as layer 3 both geometrically and materially. Note that some authors might call this a "rotating column" configuration. However, it is also customary in the literature to call it a "rotating beam". This is followed throughout the paper.

The top layer of the beam is made of an elastic material of thickness $2 h_{1}$ and Young's modulus $E_{1}$, and the bottom layer is made of an elastic material of thickness $2 h_{3}$ and Young's modulus $E_{3}$. The core is made of a linearly viscoelastic material with a shear modulus $G_{2}^{*}=G_{2}(1+j \eta)$, where $G_{2}$ is the in-phase shear modulus, $\eta$ is the core loss factor and $j=\sqrt{-1}$.

A pulsating axial load $P(t)=P_{0}+P_{1} \cos (\omega t)$ is applied at the end $x^{\prime}=b+l$ of the beam. $P_{0}$ and $P_{1}$ are, respectively, the static and dynamic load amplitudes, $\omega$ is the frequency of the dynamic load, and $t$ is time.

2.2. Derivation. The following assumptions are made for deriving the equations of motion.

(1) The beam deflection $w(x, t)$, parallel to $z$-axis is small and is the same at all points of a given cross-section.

(2) The layers are perfectly bonded so that displacements are continuous across the interfaces. The elastic face layers obey the Euler-Bernoulli beam theory.

(3) The allowance for rotary inertia is neglected while calculating the kinetic energy of the system.

(4) Shear deformation of the facings are neglected.

(5) Damping in the viscoelastic core is predominantly due to shear. Bending and extensional effects in the core are neglected.

(6) The Kerwin's assumption [23] is used.

According to the above assumption, $E_{1} A_{1} U_{1, x}+$ $E_{3} A_{3} U_{3, x}=0$

For the system

$$
\begin{gathered}
T=\frac{1}{2} m \int_{0}^{l} w_{t}^{2} d x \\
V=\frac{1}{2} \int_{0}^{l} E_{1} A_{1} U_{1, x}^{2} d x+\frac{1}{2} \int_{0}^{l} E_{3} A_{3} U_{3, x}^{2} d x \\
+\frac{1}{2} E_{1} \int_{0}^{l} I_{1}\left(\frac{\partial^{2} w}{\partial x^{2}}\right)^{2} d x+\frac{1}{2} E_{3} \int_{0}^{l} I_{3}\left(\frac{\partial^{2} w}{\partial x^{2}}\right)^{2} d x \\
+\frac{1}{2} G_{2}^{*} \int_{0}^{l} A_{2} v_{2}^{2} d x \\
+\frac{1}{2} m \Omega_{0}^{2} \int_{0}^{l}\left\{(b+x) \int_{0}^{x}\left(\frac{\partial w}{\partial x}\right)^{2} d x\right\} d x, \\
W=\frac{1}{2} \int_{0}^{l} P(t) w_{x}^{2} d x,
\end{gathered}
$$




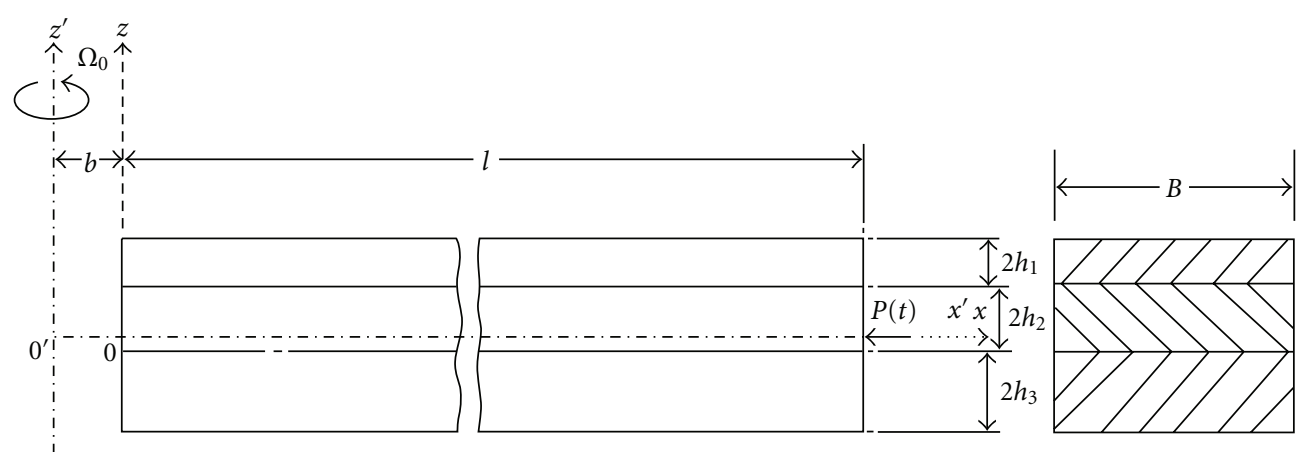

FIgURE 1: System configuration.

where $v_{2}=\left(\left(U_{1}-U_{3}-c w_{x}\right) / 2 h_{2}\right)$, which is derived according to Kerwin's assumption, where $T$ is the kinetic energy of the system, $V$ is the strain energy of the system and $W$ is the work done on the system by the external force.

Using Hamilton's principle,

$$
\delta \int_{t_{1}}^{t_{2}}(T-V+W) d t=0 .
$$

The equations of motion and the associated boundary conditions are obtained as follows:

$$
\begin{aligned}
& \ddot{w}+\left(E_{1} I_{1}+E_{3} I_{3}\right) \\
& {\left[\frac{1}{m}+\frac{3 \Omega_{0}^{2}}{2\left(E_{1} A_{1}+E_{3} A_{3}\right)}\left\{f-(x+b)^{2}\right\}\right] w^{\prime \prime \prime \prime}} \\
& -3 \frac{E_{1} I_{1}+E_{3} I_{3}}{E_{1} A_{1}+E_{3} A_{3}} \Omega_{0}^{2}(x+b) w^{\prime \prime \prime} \\
& +\left[-3 \frac{E_{1} I_{1}+E_{3} I_{3}}{2\left(E_{1} A_{1}+E_{3} A_{3}\right)} \Omega_{0}^{2}-\frac{1}{2} \Omega_{0}^{2}\left\{f-(x+b)^{2}\right\}\right. \\
& \left.\times \frac{G_{2}^{*} A_{2} c^{2}}{m\left(2 h_{2}\right)^{2}}+\frac{P(t)}{m}\right] w^{\prime \prime}+\frac{1}{2} \Omega_{0}^{2}(x+b) w^{\prime} \\
& +\frac{G_{2}^{*} A_{2} c(1+\alpha)}{m\left(2 h_{2}\right)^{2}} u_{1}^{\prime}=0 \\
& u_{1}^{\prime \prime}-\frac{G_{2}^{*} A_{2}(1+\alpha)}{\left(2 h_{2}\right)^{2}\left(E_{1} A_{1}+\alpha^{2} E_{3} A_{3}\right)}\left\{(1+\alpha) u_{1}-c w^{\prime}\right\}=0 . \\
& w^{\prime \prime}=0 \text { or } w^{\prime}=0, \\
& \left(E_{1} I_{1}+E_{3} I_{3}\right) \frac{\partial}{\partial x}\left[\left\{1+\frac{3 m \Omega_{0}^{2}}{2\left(E_{1} A_{1}+E_{3} A_{3}\right)}\left(f-(x+b)^{2}\right)\right\} w^{\prime \prime}\right] \\
& -\left[\frac{m \Omega_{0}^{2}}{2}\left\{f-(x+b)^{2}\right\}+\frac{G_{2}^{*} A_{2} c^{2}}{\left(2 h_{2}\right)^{2}}+P(t)\right] w^{\prime} \\
& +\frac{G_{2}^{*} A_{2} c(1+\alpha)}{\left(2 h_{2}\right)^{2}} u_{1}=0 \text {, }
\end{aligned}
$$

or,

$$
\begin{gathered}
w=0 \\
u_{1}^{\prime}=0 \quad \text { or } u_{1}=0 .
\end{gathered}
$$

Introducing the nondimensional variables $\bar{x}=x / l, \bar{w}=$ $w / l, \bar{u}_{1}=u_{1} / l$, and $\bar{t}=t / t_{0}$, where $t_{0}=\sqrt{m l^{4} /\left(E_{1} I_{1}+E_{3} I_{3}\right)}$ and simplifying, the following nondimensional equations of motion are obtained:

$$
\begin{aligned}
& \ddot{\bar{w}}+\left[1+\frac{\lambda_{0}^{2}\left(1+E_{31} h_{31}^{3}\right)}{l_{h_{1}}^{2}\left(1+E_{31} h_{31}\right)}\left\{\frac{f}{l_{2}}-(\bar{x}+\bar{b})^{2}\right\}\right] \bar{w}^{\prime \prime \prime \prime} \\
& -\frac{2 \lambda_{0}^{2}\left(1+E_{31} h_{31}^{3}\right)}{l_{h 1}^{2}\left(1+E_{31} l_{31}\right)}(\bar{x}+\bar{b}) \bar{w}^{\prime \prime \prime} \\
& +\left[\frac{\lambda_{0}^{2}\left(1+E_{31} h_{31}^{3}\right)}{l_{h 1}^{2}\left(1+E_{31} l_{31}\right)}-\lambda_{0}^{2}\left\{\frac{f}{l^{2}}-(\bar{x}+\bar{b})^{2}\right\}\right. \\
& \left.-3 g^{*}\left(1+\frac{h_{12}+h_{32}}{2}\right)^{2}+\bar{P}(\bar{t})\right] \bar{w}^{\prime \prime} \\
& +\lambda_{0}^{2}(\bar{x}+\bar{b}) \bar{w}^{\prime}+\frac{3}{2} g^{*} l_{h 1} h_{12}\left(1+\frac{h_{12}+h_{32}}{2}\right) \\
& \times(1+\alpha) \bar{u}_{1}^{\prime}=0 \text {, } \\
& \bar{u}_{1}^{\prime \prime}-\frac{g^{*}}{4} h_{12}^{2} \frac{1+E_{31} h_{31}^{3}}{1+\alpha^{2} E_{31} h_{31}}(1+\alpha) \\
& \times\left[(1+\alpha) \bar{u}_{1}-\left(2 \frac{\left(1+\left(\left(h_{12}+h_{32}\right) / 2\right)\right)}{\left(l_{h 1} h_{12}\right)}\right) \bar{w}^{\prime}\right]=0 .
\end{aligned}
$$




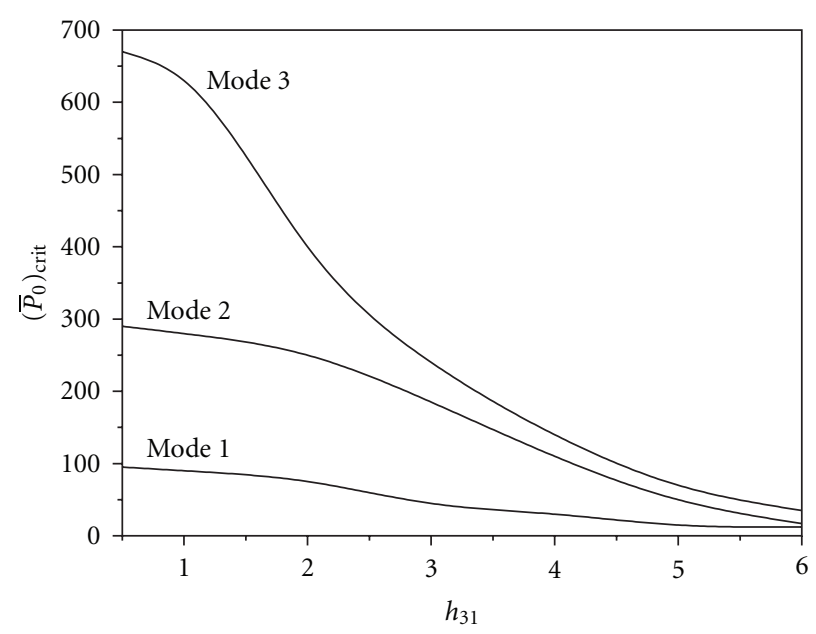

(a)

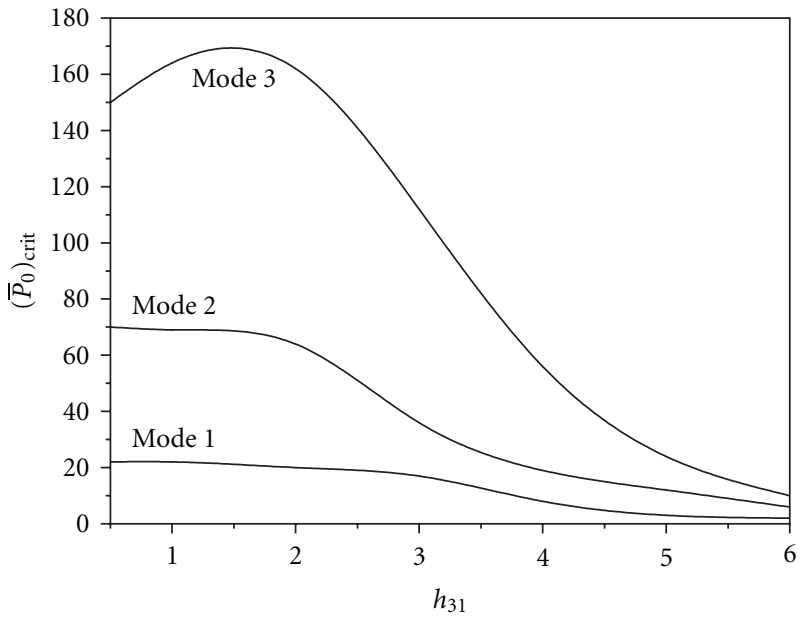

(b)

FIGURE 2: (a) Variation static buckling loads with $h_{31}$ (pinned-pinned). (b) Variation static buckling loads with $h_{31}$ (clamped-free).

The associated nondimensional boundary conditions at $\bar{x}=0$ and $\bar{x}=1$ are

$$
\begin{gathered}
\bar{w}^{\prime \prime}=0 \text { or } \quad \bar{w}^{\prime}=0, \\
\frac{\partial}{\partial x}\left[\left(1+\lambda_{1}^{2}\left\{\frac{f}{l^{2}}-(\bar{x}+\bar{b})^{2}\right\}\right) \bar{w}^{\prime \prime}\right] \\
-\left[\lambda_{0}^{2}\left\{\frac{f}{l^{2}}-(\bar{x}+\bar{b})^{2}\right\} \bar{w}^{\prime}\right. \\
\left.+3 g^{*}\left(1+\frac{h_{12}+h_{32}}{2}\right)^{2}+\bar{P}(\bar{t})\right] \bar{w}^{\prime} \\
+\frac{3}{2} g^{*} l_{h 1} h_{12}(1+\alpha)\left(1+\frac{h_{12}+h_{32}}{2}\right) \bar{u}_{1}=0,
\end{gathered}
$$

or

$$
\begin{aligned}
& w=0, \\
& \bar{u}_{1}^{\prime}=0 \quad \text { or } \quad \bar{u}_{1}=0
\end{aligned}
$$

The various parameters. are defined as

$$
\begin{gathered}
E_{31}=\frac{E_{3}}{E_{1}}, \\
h_{31}=\frac{h_{3}}{h_{1}}, \\
l_{h 1}=\frac{l}{h_{1}}, \\
g_{12}^{*}=\frac{h_{1}}{h_{2}}, \\
=\frac{(1+j \eta)}{E_{1}\left(1+E_{31}^{*} h_{31}^{3}\right)},
\end{gathered}
$$

where $g$ being the shear parameter

$$
\begin{aligned}
& \lambda_{0}=\sqrt{\left(\frac{m \Omega_{0}^{2} l^{4}}{2\left(E_{1} I_{1}+E_{3} I_{3}\right)}\right)}, \\
& \lambda_{1}=\sqrt{\left(\frac{3 m \Omega_{0}^{2} l^{2}}{2\left(E_{1} A_{1}+E_{3} A_{3}\right)}\right)} .
\end{aligned}
$$

These are rotation parameters

$$
\begin{aligned}
\bar{P}(\bar{t}) & =\bar{P}_{0}+\bar{P}_{1} \cos (\bar{\omega} \bar{t}) \\
& =\frac{\left(P(t) l^{2}\right)}{\left(E_{1} I_{1}+E_{3} I_{3}\right)} .
\end{aligned}
$$

This is the nondimensional load.

2.3. Approximate Solution. Approximate solution to the nondimensional equations of motion are assumed as

$$
\begin{gathered}
\bar{w}(\bar{x}, \bar{t})=\sum_{i=1}^{i=N} f_{i}(\bar{t}) w_{i}(\bar{x}), \\
\bar{u}_{1}(\bar{x}, \bar{t})=\sum_{k=N+1}^{k=2 N} f_{k}(\bar{t}) u_{1 k}(\bar{x}),
\end{gathered}
$$

where $f_{r}(r=1,2, \ldots, 2 N)$ are the generalized coordinates and $w_{i}$ and $u_{1 k}$ are the coordinate functions satisfying as many boundary conditions as possible [24]. For the pinnedpinned case, the shape functions chosen are

$$
\begin{aligned}
w_{i}(\bar{x}) & =\sin (i \pi \bar{x}), \\
u_{1 k}(\bar{x}) & =\cos (\bar{k} \pi \bar{x}), \\
\bar{k} & =k-N .
\end{aligned}
$$

For $i=1,2, \ldots, N$, and $k=N+1, N+2, \ldots, 2 N$. 
For the clamped-free case, the approximating functions are

$$
\begin{gathered}
w_{i}(\bar{x})=(i+2)(i+3) \bar{x}^{i+1}-2 i(i+3) \bar{x}^{i+2}+i(i+1) \bar{x}^{i+2}, \\
u_{1 k}(\bar{x})=\bar{x}^{\bar{k}}-\left[\frac{\bar{k}}{\bar{k}+1}\right] \bar{x}^{k+1} .
\end{gathered}
$$

Substitution of the series solutions in the nondimensional equations of motion and subsequent application of the general Galerkin method [24] leads to the following matrix equations of motion:

$$
\begin{gathered}
{[m]\left\{\ddot{f}_{j}\right\}+\left[k_{11}\right]\left\{f_{j}\right\}+\left[k_{12}\right]\left\{f_{l}\right\}=\{0\},} \\
{\left[k_{22}\right]\left\{f_{l}\right\}+\left[k_{21}\right]\left\{f_{j}\right\}=\{0\},}
\end{gathered}
$$

where $j=1,2, \ldots, N$ and $l=N+1, \ldots, 2 N$. The various matrix elements are given by

$$
\begin{aligned}
& m_{i j}=\int_{0}^{1} w_{i} w_{j} d \bar{x} \\
& k_{11 i j}=\int_{0}^{1}\left[1+\lambda_{1}\left\{\frac{f}{l^{2}}-(\bar{x}+\bar{b})^{2}\right\}\right] w_{i}^{\prime \prime} w_{j}^{\prime \prime} d \bar{x} \\
&+\lambda_{0}^{2} \int_{0}^{1}\left\{\frac{f}{l^{2}}-(\bar{x}+\bar{b})^{2}\right\} w_{i}^{\prime} w_{j}^{\prime} d \bar{x} \\
&+\left\{3 g^{*}\left(1+\frac{h_{12}+h_{32}}{2}\right)^{2}-\bar{P}(\bar{t})\right\}\left(\int_{0}^{1} w_{i}^{\prime} w_{j}^{\prime} d \bar{x}\right) \\
& k_{12 j l}=-\left(\frac{3}{2}\right) g^{*} l_{h 1} h_{12}(1+\alpha)\left(1+\frac{h_{12}+h_{32}}{2}\right) \\
& \times\left(\int_{0}^{1} u_{1 l} w_{j}^{\prime} d \bar{x}\right), \\
& k_{21 l i}=-\left(\frac{3}{2}\right) g^{*} l_{h 1} h_{12}(1+\alpha)\left(1+\frac{h_{12}+h_{32}}{2}\right) \\
&+\left(\int_{0}^{1} u_{1 l} w_{i}^{\prime} d \bar{x}\right), \\
& k_{22 k l}= 3 l_{h 1}^{2} \frac{\left(1+\alpha^{*} E_{31} h_{31}^{2} h_{12}^{2}(1+\alpha)^{2}\left(\int_{0}^{1} u_{1 k} u_{1 l} d \bar{x}\right)\right.}{\left.u_{1 k}^{\prime} u_{1 l}^{\prime} d \bar{x}\right)} \\
&\left.+E_{31} h_{31}^{3}\right) \\
&+(1) \\
&+(1) \\
&
\end{aligned}
$$

From (16)

$$
\left\{f_{l}\right\}=-\left[k_{22}\right]^{-1}\left[k_{21}\right]\left\{f_{j}\right\},
$$

where

$$
\left[k_{21}\right]=\left[k_{12}\right]^{T} \text {. }
$$

Substitution of above in (15) and subsequent simplification leads to

$$
[m]\left\{\ddot{f}_{j}\right\}+\left[[k]-\bar{P}_{0}[H]\right]\left\{f_{j}\right\}-\bar{P}_{1} \cos (\omega \bar{t})[H]\left\{f_{j}\right\}=\{0\},
$$

where

$$
\begin{gathered}
{[k]=[\bar{k}]-\left[k_{12}\right]\left[k_{22}\right]^{-1}\left[k_{12}\right]^{T},} \\
\bar{k}_{i j}=\int_{0}^{1}\left[1+\lambda_{1}\left\{\frac{f}{l^{2}}-(\bar{x}+\bar{b})^{2}\right\}\right] w_{i}^{\prime \prime} w_{j}^{\prime \prime} d \bar{x} \\
+\lambda_{0}^{2} \int_{0}^{1}\left\{\frac{f}{l^{2}}-(\bar{x}+\bar{b})^{2}\right\} \times w_{i}^{\prime} w_{j}^{\prime} d \bar{x} \\
+3 g^{*}\left(1+\frac{h_{12}+h_{32}}{2}\right)^{2} \int_{0}^{1} w_{i}^{\prime} w_{j}^{\prime} d \bar{x}, \\
H_{i j}=\int_{0}^{1} w_{i}^{\prime} w_{j}^{\prime} d \bar{x} .
\end{gathered}
$$

2.4. Static Buckling Loads. Substitution of $\bar{P}_{1}=0$ and $\left\{\ddot{f}_{j}\right\}=$ $\{0\}$ in (20) leads to the eigen value problem $[k]^{-1}[H]\left\{f_{j}\right\}=$ $1 / P_{0}\left\{f_{j}\right\}$. The static buckling loads $\left(\bar{P}_{0}\right)_{\text {crit }}$ for the first few modes are obtained as the real parts of the reciprocals of the eigen values of $[k]^{-1}[H]$.

\section{Numerical Results and Discussion}

Numerical results were obtained for various values of the non-dimensional geometric parameters $h_{31}, h_{12}, l_{h 1}, \bar{b}$, the modulus ratio $G_{2} / E_{1}$ and the rotation parameter $\lambda_{1}$. The following values of parameters are used unless otherwise stated: $\eta=0.05, h_{31}=h_{12}=1.0, l_{h 1}=40, b=0.05$, $G_{2} / E_{1}=0.001, g=0.1, \lambda_{0}=0.05$, and $\lambda_{1}=0.1$.

It should be noted that Figures 2(a), 3(a), 4(a), 5(a), $6(\mathrm{a})$, and $7(\mathrm{a})$ are for the pinned-pinned case and Figures 2(b), 3(b), 4(b), 5(b), 6(b), and 7(b) are for the clamped-free configuration. Figures from 2(a), 2(b)-7(a), and 7(b) show the variation of the first three nondimensional static buckling loads, $\left(\bar{P}_{0}\right)_{\text {crit }}$ with $h_{31}, h_{12}, l_{h 1}, \bar{b}, G_{2} / E_{1}$, and $\lambda_{1}$, respectively. The variation of these loads with $g$ and $\lambda_{0}$ are similar to those for $G_{2} / E_{1}$ and $l_{h 1}$, respectively, and are not shown.

With an increase in $h_{31}$ (Figure $2(a)$ ), the buckling loads are seen to decrease monotonically for the pinned-pinned case. For the clamped-free case (Figure 2(b)), these first increase and then decrease. The rate of decrease is maximum for the highest mode for moderate $h_{31}$ values.

As $h_{12}$ (Figures 3(a) and 3(b)) is increased, $\left(\bar{P}_{0}\right)_{\text {crit }}$ for the three modes shows a decreasing trend for low values of $h_{12}$. It remains fairly constant for moderate values of $h_{12}$ and increases for higher values.

It is observed that $\left(\bar{P}_{0}\right)_{\text {crit }}$ increases nonlinearly with $l_{h 1}$ for three modes (Figures 4(a) and 4(b)).

The critical loads are almost constant over the entire range of $\bar{b}$ (Figures 5(a) and 5(b)).

For increasing the $G_{2} / E_{1}$, Figures $6(\mathrm{a})$ and $6(\mathrm{~b})$, the $\left(\bar{P}_{0}\right)_{\text {crit }}$ values are initially constant and rise appreciably for higher values of $G_{2} / E_{1}$, the rate of increase being higher for the higher modes.

It is seen that $\left(\bar{P}_{0}\right)_{\text {crit }}$ is almost constant over a wide range of $\lambda_{1}$ (Figures $7(\mathrm{a})$ and $7(\mathrm{~b})$ ) and decrease slightly for the values of $\lambda_{1}$ greater than 0.1 . 


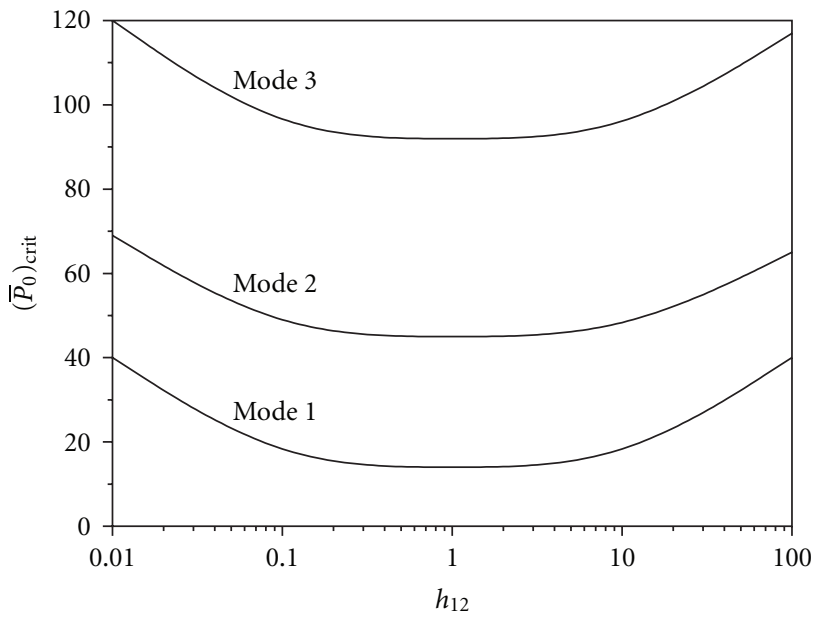

(a)

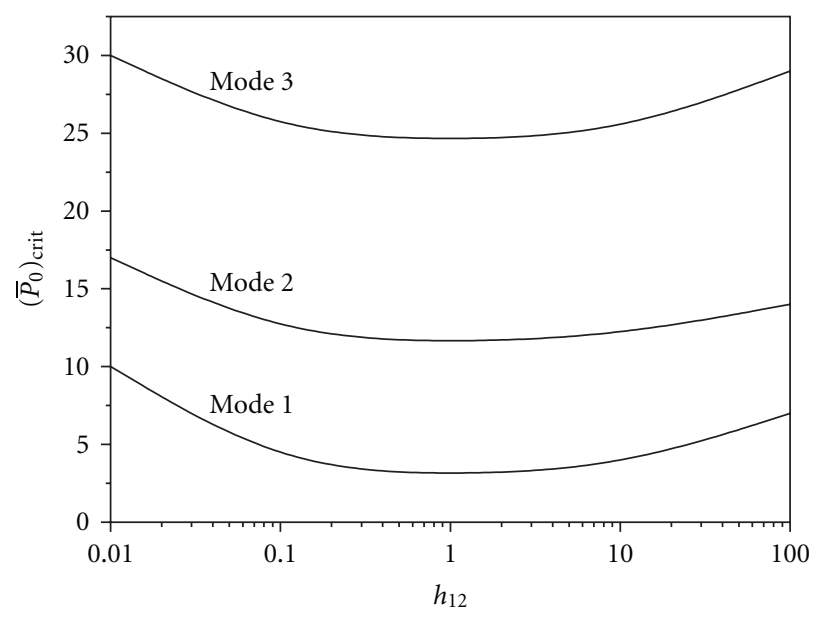

(b)

FIgURE 3: (a) Variation static buckling loads with $h_{12}$ (pinned-pinned). (b) Variation static buckling loads with $h_{12}$ (clamped-free).

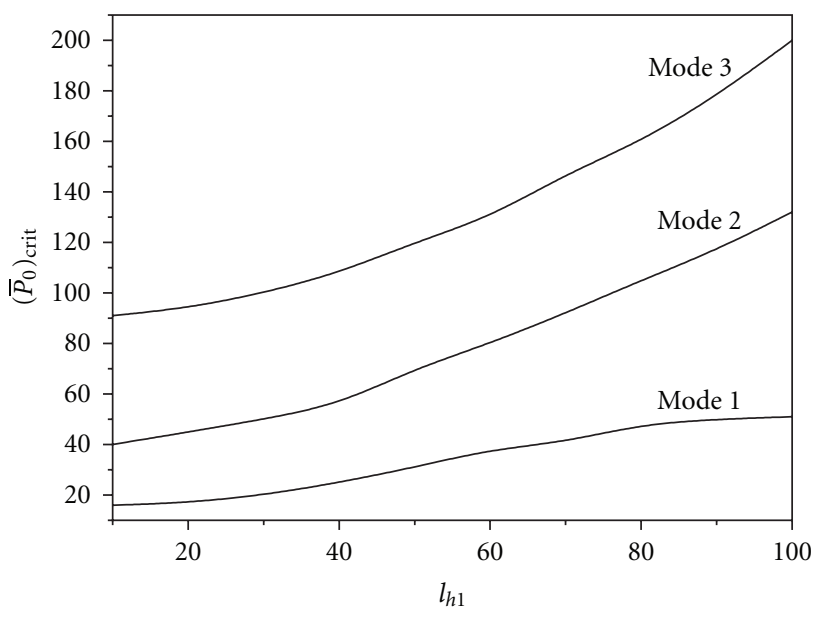

(a)

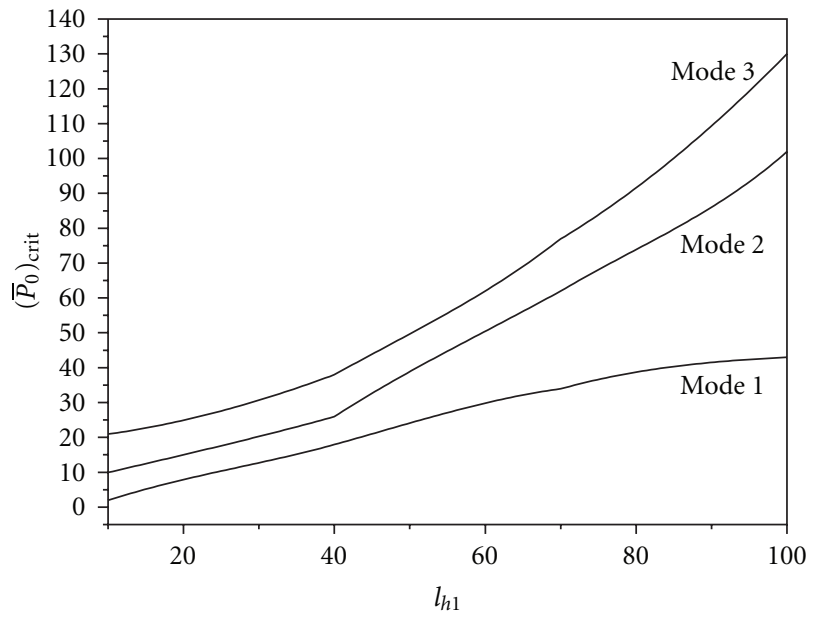

(b)

FIGURE 4: (a) Variation static buckling loads with $l_{h 1}$ (pinned-pinned). (b) Variation static buckling loads with $l_{h 1}$ (clamped-free).

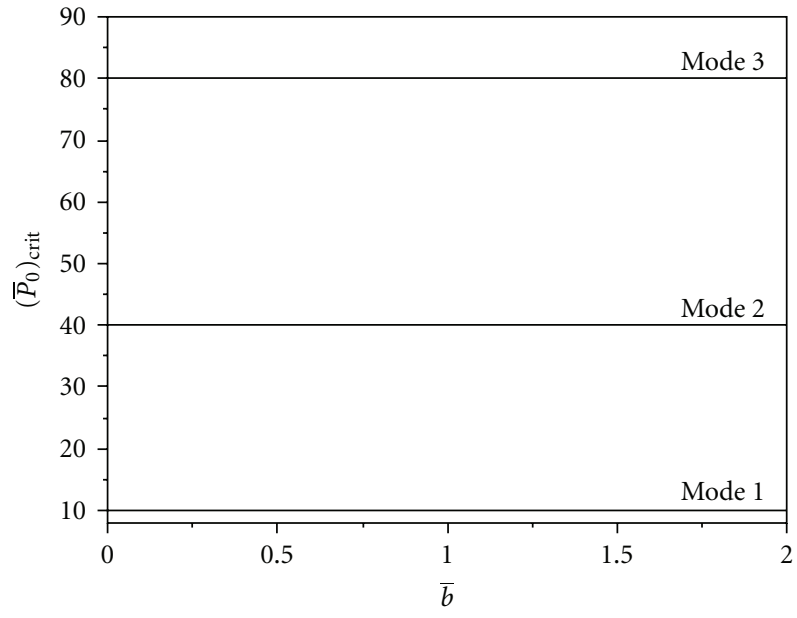

(a)

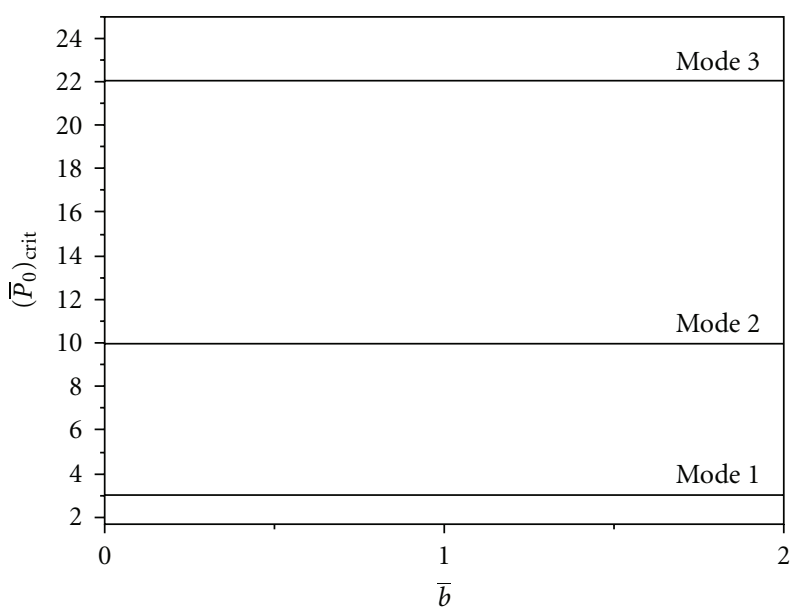

(b)

FIGURE 5: (a) Variation static buckling loads with $\bar{b}$ (pinned-pinned). (b) Variation static buckling loads with $\bar{b}$ (clamped-free). 


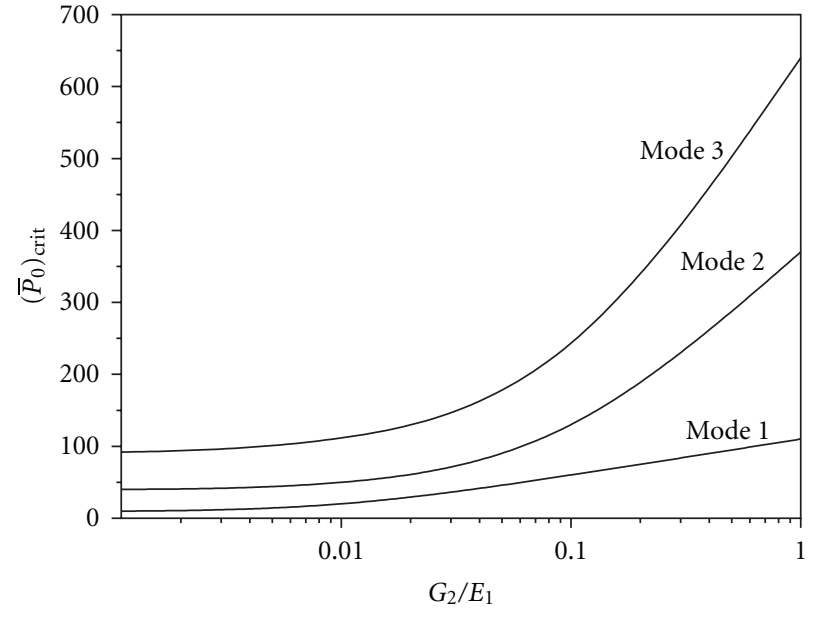

(a)

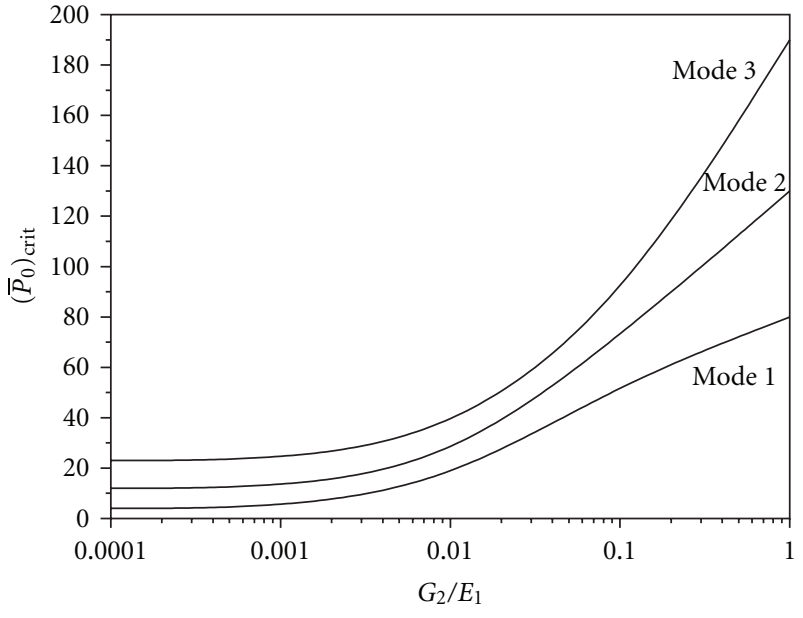

(b)

Figure 6: (a) Variation static buckling loads with $G_{2} / E_{1}$ (pinned-pinned). (b) Variation static buckling loads with $G_{2} / E_{1}$ (clamped-free).

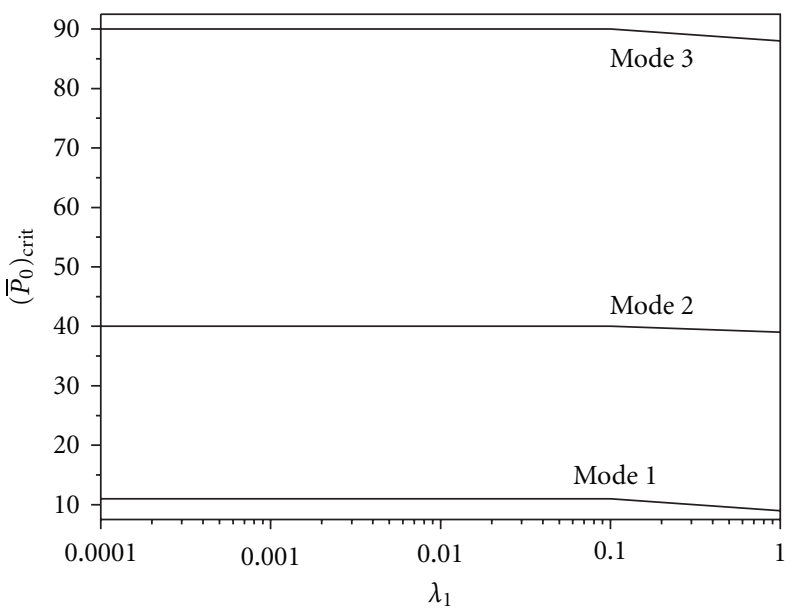

(a)

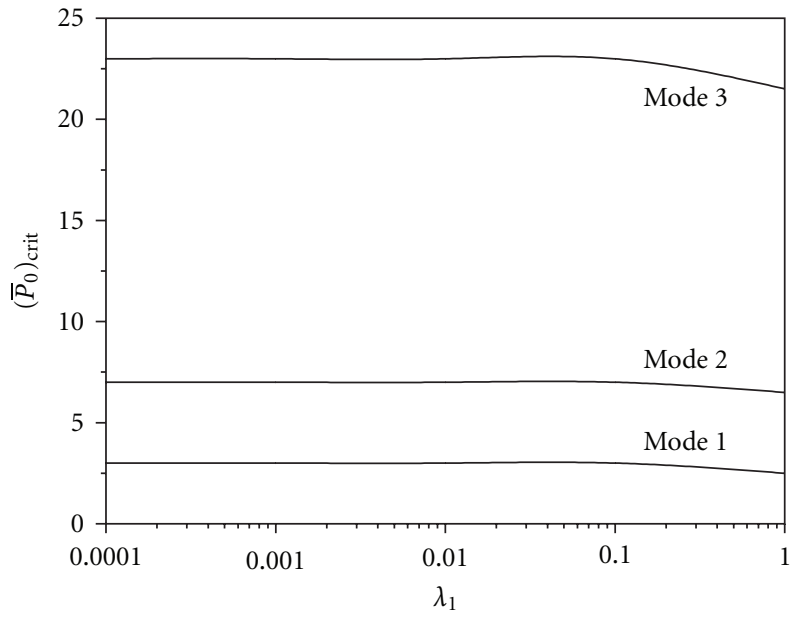

(b)

FIGURE 7: (a) Variation static buckling loads with $\lambda_{1}$ (pinned-pinned). (b) Variation static buckling loads with $\lambda_{1}$ (clamped-free).

\section{Conclusions}

In this paper, the static stability of an asymmetric threelayered rotating sandwich beam with viscoelastic core has been considered. The beam is subjected to an axial pulsating load. Both pinned-pinned and clamped-free configurations have been considered. An increase in $h_{31}$ is seen to have a detrimental effect on the nondimensional static buckling loads. Hence, a symmetric beam is seen to have better resistance against static buckling. Over a wide range of values, $h_{12}$ is seen to have little effect upon the buckling loads. However, for small values, it has a detrimental effect, and for large values, it improves the buckling loads. $l_{h 1}, G_{2} / E_{1}, \lambda_{0}$, and $g$ improve static stability, especially for large values of the parameters. The buckling loads are seen to be almost independent of $\bar{b}$ and $\lambda_{1}$.

\section{Nomenclature}

$A_{i}(i=1,2,3)$ : Areas of cross section of a three layered beam, $i=1,2$, and 3 for top, middle and bottom layer, respectively,

$B: \quad$ Width of beam

$b$ : $\quad$ Distance of nearer end of the beam from the axis of rotation

$\bar{b}: \quad b / l$

$c: \quad h_{1}+2 h_{2}+h_{3}$

$E_{i}(i=1,2,3)$ : Young's modulli, $i=1,2,3$ for top, middle and bottom layer, respectively,

$\ddot{f}_{j}: \quad \partial^{2} f_{j} / \partial \bar{t}^{2}$

$G_{2}$ : $\quad$ In-phase shear modulus of the viscoelastic core 


\begin{tabular}{|c|c|}
\hline$G_{2}^{*}:$ & $\begin{array}{l}G_{2}(1+j \eta), \text { complex shear modulus of } \\
\text { core }\end{array}$ \\
\hline$g^{*}:$ & $g(1+j \eta)$, complex shear parameter \\
\hline & Shear parameter \\
\hline $2 h_{i}(i=1,2,3)$ & $\begin{array}{l}\text { Thickness of the } i \text { th layer, } i=1,2 \text { and } 3 \\
\text { for top, middle and bottom layer, } \\
\text { respectively }\end{array}$ \\
\hline$h_{12}$ : & $h_{1} / h_{2}$ \\
\hline$h_{31}:$ & $h_{3} / h_{1}$ \\
\hline$I_{i}(i=1,2,3)$ : & $\begin{array}{l}\text { Second moments of area of cross } \\
\text { section about a relevant axis, } i=1,2 \\
\text { and } 3 \text { for top, middle, and bottom layer }\end{array}$ \\
\hline & $\sqrt{-1}$ \\
\hline 1 & Beam length \\
\hline$l_{h 1}:$ & $l / h_{1}$ \\
\hline$m:$ & Mass/unit length of beam \\
\hline $\bar{P}_{1}:$ & $\begin{array}{l}\text { Nondimensional amplitude for the } \\
\text { dynamic loading }\end{array}$ \\
\hline$\left(\bar{P}_{0}\right)_{\text {crit: }}:$ & $\begin{array}{l}\text { Nondimensional static critical buckling } \\
\text { load }\end{array}$ \\
\hline & Time \\
\hline l. & Nondimensional time \\
\hline$u_{1}(x, t), U_{1}(x, t):$ & $\begin{array}{l}\text { Axial displacement at the middle of the } \\
\text { top layer of beam }\end{array}$ \\
\hline$u_{3}(x, t), U_{3}(x, t):$ & $\begin{array}{l}\text { Axial displacement at the middle of the } \\
\text { bottom layer of beam }\end{array}$ \\
\hline $\begin{array}{l}w(x, t): \\
w^{\prime}:\end{array}$ & $\begin{array}{l}\text { Transverse deflection of beam } \\
\partial w / \partial x\end{array}$ \\
\hline$w^{\prime \prime}:$ & $\partial^{2} w / \partial x^{2}$ \\
\hline $\bar{w}:$ & $w / l$ \\
\hline$\ddot{\bar{w}}:$ & $\partial^{2} \bar{w} / \partial \bar{t}^{2}$ \\
\hline $\bar{w}^{\prime \prime}:$ & $\partial^{2} \bar{w} / \partial \bar{x}^{2}$ \\
\hline$t_{0}:$ & $\sqrt{m l^{4} /\left(E_{1} I_{1}+E_{3} I_{3}\right)}$ \\
\hline$u_{1}^{\prime}:$ & $\partial u_{1} / \partial x$ \\
\hline$\frac{1}{u_{1}}{ }^{\prime \prime}:$ & $\partial^{2} \bar{u}_{1} / \partial \bar{x}^{2}$ \\
\hline$f:$ & $\begin{array}{l}(l+b)^{2}, \text { for beam free at } \\
x=l,=\left(l^{3} / 3\right)+b^{2}+b l \text { for all other } \\
\text { cases }\end{array}$ \\
\hline$\eta:$ & Core-loss factor \\
\hline$\lambda_{0}:$ & Rotation parameter \\
\hline$\lambda_{1}:$ & Rotation parameter \\
\hline$(\Phi):$ & A null matrix \\
\hline $\bar{\omega}:$ & $\omega t_{0}$ \\
\hline$\omega:$ & Frequency of forcing function \\
\hline $\bar{\omega}:$ & Nondimensional forcing frequency \\
\hline$\Omega_{0}:$ & Speeds of rotation \\
\hline $\bar{\Omega}_{0}:$ & Nondimensional rotation parameters \\
\hline
\end{tabular}

\section{References}

[1] R. B. Bhat, "Transverse vibrations of a rotating uniform cantilever beam with tip mass as predicted by using beam characteristic orthogonal polynomials in the Rayleigh-Ritz method," Journal of Sound and Vibration, vol. 105, no. 2, pp. 199-210, 1986.

[2] W. H. Liu and F. H. Yeh, "Vibrations of non-uniform rotating beams," Journal of Sound and Vibration, vol. 119, no. 2, pp. 379-384, 1987.
[3] A. Unger and M. A. Brull, "Parametric instability of a rotating shaft due to pulsating torque," Journal of Applied Mechanics, Transactions ASME, vol. 48, no. 4, pp. 948-958, 1981.

[4] D. C. Kammer and A. L. Schlack, "Dynamic response of a radial beam with nonconstant angular velocity," Journal of Vibration, Acoustics, Stress, and Reliability in Design, vol. 109, no. 2, pp. 138-143, 1987.

[5] N. Sri Namachchivaya, "Mean square stability of a rotating shaft under combined harmonic and stochastic excitations," Journal of Sound and Vibration, vol. 133, no. 2, pp. 323-336, 1989.

[6] H. F. Bauer and W. Eidel, "Vibration of a rotating uniform beam, Part-II: orientation perpendicular to the axis of rotation," Journal of Sound and Vibration, vol. 122, no. 2, pp. 357375, 1988.

[7] B. A. H. Abbas, "Vibrations of Timoshenko beams with elastically restrained ends," Journal of Sound and Vibration, vol. 97, no. 4, pp. 541-548, 1984.

[8] B. A. H. Abbas and J. Thomas, "Dynamic stability of Timoshenko beams resting on an elastic foundation," Journal of Sound and Vibration, vol. 108, pp. 25-32, 1986.

[9] O. A. Bauchau and C. H. Hong, "Nonlinear response and stability analysis of beams using finite elements in time," AIAA Journal, vol. 26, no. 9, pp. 1135-1142, 1988.

[10] R. C. Kar and T. Sujata, "Dynamic stability of a rotating beam with various boundary conditions," Computers and Structures, vol. 40, no. 3, pp. 753-773, 1991.

[11] R. C. Kar and T. Sujata, "Dynamic stability of a rotating, pretwisted and preconed cantilever beam including coriolis effects," Computers and Structures, vol. 42, no. 5, pp. 741-750, 1992.

[12] T. H. Tan, H. P. Lee, and G. S. B. Leng, "Parametric instability of spinning pretwisted beams subjected to sinusoidal compressive axial loads," Computers and Structures, vol. 66, no. 6, pp. 745-764, 1998.

[13] B. Pratiher and S. K. Dwivedy, "Parametric instability of a cantilever beam with magnetic field and periodic axial load," Journal of Sound and Vibration, vol. 305, no. 4-5, pp. 904-917, 2007.

[14] S. K. Dwivedy, K. C. Sahu, and S. Babu, "Parametric instability regions of three-layered soft-cored sandwich beam using higher-order theory," Journal of Sound and Vibration, vol. 304, no. 1-2, pp. 326-344, 2007.

[15] D. Y. Zheng, F. T. K. Au, and Y. K. Cheung, "Vibration of vehicle on compressed rail on viscoelastic foundation," Journal of Engineering Mechanics, vol. 126, no. 11, pp. 1141-1147, 2000.

[16] A. V. Metrikine and S. N. Verichev, "Instability of vibrations of a moving two-mass oscillator on a flexibly supported Timoshenko beam," Archive of Applied Mechanics, vol. 71, no. 9, pp. 613-624, 2001.

[17] A. V. Metrikine and S. N. Verichev, "Instability of vibrations of a mass that moves uniformly along a beam on a periodically inhomogeneous foundation," Journal of Sound and Vibration, vol. 260, no. 5, pp. 901-925, 2003.

[18] R. Ghosh, S. Dharmavaram, K. Ray, and P. Dash, "Dynamic stability of a viscoelastically supported sandwich beam," Structural Engineering and Mechanics, vol. 19, no. 5, pp. 503517, 2005.

[19] C. Y. Lin and L. W. Chen, "Dynamic stability of rotating composite beams with a viscoelastic core," Composite Structures, vol. 58, no. 2, pp. 185-194, 2002. 
[20] C. Y. Lin and L. W. Chen, "Dynamic stability of a rotating beam with a constrained damping layer," Journal of Sound and Vibration, vol. 267, no. 2, pp. 209-225, 2003.

[21] P. R. Dash, B. B. Maharathy, R. Mallick, B. B. Pani, and K. Ray, "Parametric instability of an asymmetric rotating sandwich beam," Journal of Aerospace Sciences and Technologies, vol. 60, no. 4, pp. 292-309, 2008.

[22] H. Saito and K. Otomi, "Parametric response of viscoelastically supported beams," Journal of Sound and Vibration, vol. 63, no. 2, pp. 169-178, 1979.

[23] E. M. Kerwin Jr., "Damping of flexural waves by a constrained viscoelastic layer," The Journal of the Acoustical society of America, vol. 31, pp. 952-962, 1959.

[24] H. Leipholz, Stability Theory, John Wiley \& Sons, Chichester, UK, 2nd edition, 1987. 

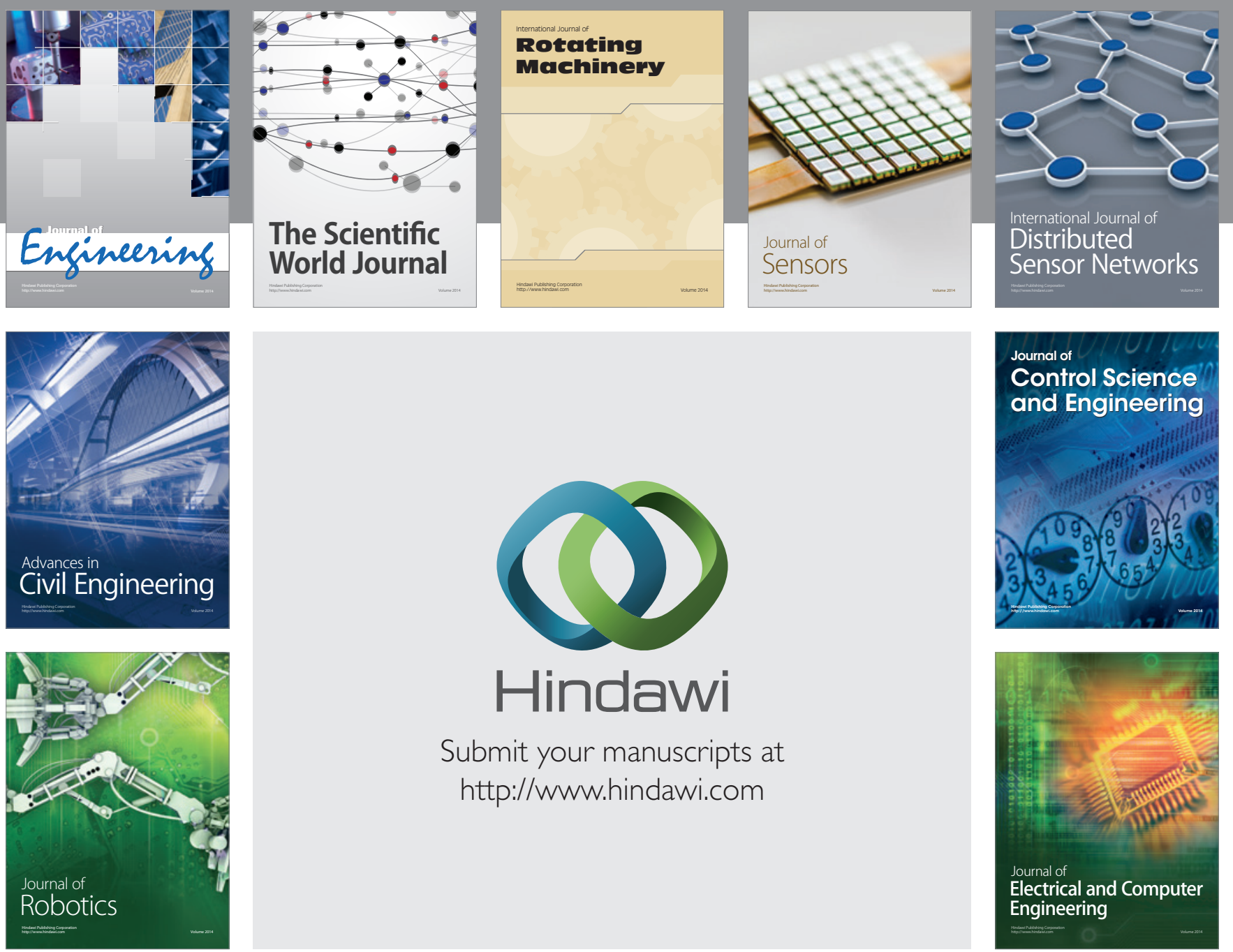

Submit your manuscripts at

http://www.hindawi.com
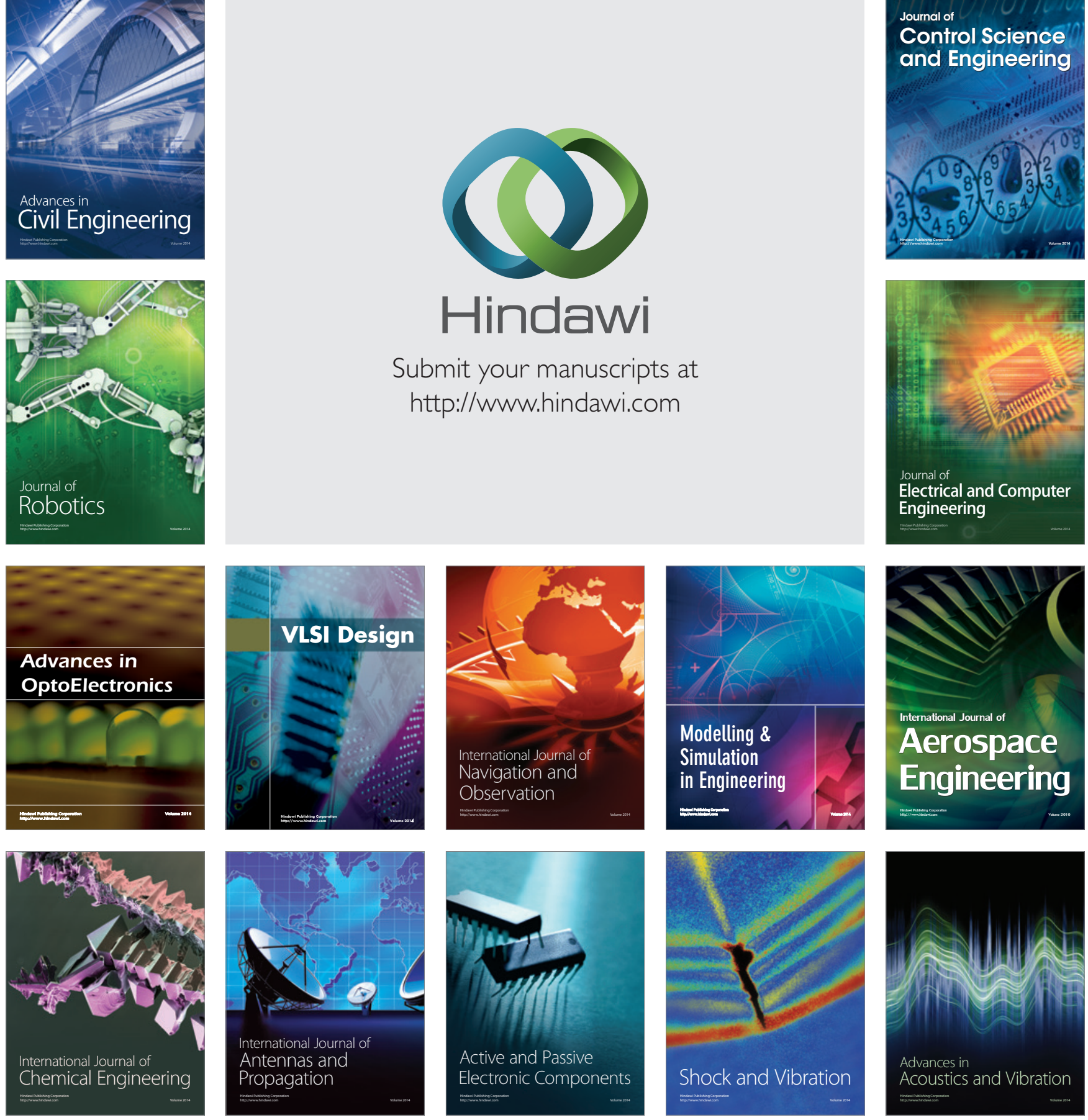